\title{
X-Ray, Thermal and Mechanical Studies of Potassium Acid Phthalate Single Crystals Added with Aspartic Acid/L-Citrulline
}

\author{
C. AMUTHAMBIGAI, C. K. MAHADEVAN and X. SAHAYA SHAJAN*
}

Centre for Scientific and Applied Research, PSN College of Engineering and Technology, Tirunelveli-627152, Tamilnadu, India

shajan89@gmail.com

Received 12 August 2015 / Accepted 12 September 2015

\begin{abstract}
Potassium acid phthalate (KAP) is an interesting semi-organic optical material. Optically transparent good quality single crystals of pure and amino acid added KAP single crystals were grown by conventional slow evaporation technique at $32{ }^{\circ} \mathrm{C}$ and characterized to study the thermal and mechanical stability of the crystal. The x-ray diffraction analysis confirms the presence of amino acid molecules in the KAP crystal matrix in the case of amino acid added KAP single crystals. The thermogravimetric (TG/DTG) and microhardness measurements indicate that the amino acid addition significantly tunes the thermal stability and mechanical strength of the KAP crystal.
\end{abstract}

Keywords: Semi-organic optical materials, X-ray diffraction, Thermal stability, Mechanical property

\section{Introduction}

Single crystals of semi-organic optical materials have been grown and characterized with much interest in the last few decades due to their importance in industrial applications. Crystals of metal hydrogen phthalates $\left(\mathrm{C}_{6} \mathrm{H}_{4} \mathrm{COOHCOOM}, \mathrm{M}\right.$ representing alkali metals) are used as analyzers, monochromators and modulators in soft x-ray spectrometers ${ }^{1}$. These crystals have covalent, ionic, van der Waals and hydrogen bonds. Among these, potassium hydrogen phthalate or potassium acid phthalate (KAP) is found to be very interesting.

KAP crystallizes in the orthorhombic crystal system with space group Pca2 $2_{1}$ and KAP crystal exhibits piezoelectric, pyroelectric, ferroelectric, elastic and nonlinear optical (NLO) properties with long term stability in devices ${ }^{2}$. A good number of reports are available on the growth and characterization of pure and impurity added (doped) KAP single crystals $^{3-8}$. Significant tuning of optical, thermal and mechanical properties of KAP has been observed on doping with amino acids like glycine $\left(\mathrm{C}_{2} \mathrm{H}_{5} \mathrm{NO}_{2}\right)$, L-alanine $\left(\mathrm{C}_{3} \mathrm{H}_{7} \mathrm{NO}_{2}\right)$, L-tyrosine $\left(\mathrm{C}_{9} \mathrm{H}_{11} \mathrm{NO}_{3}\right)$, l-lysine $\left(\mathrm{C}_{6} \mathrm{H}_{15} \mathrm{~N}_{2} \mathrm{O}_{2}\right), d L$-alanine $\left(\mathrm{C}_{3} \mathrm{H}_{7} \mathrm{NO}_{2}\right)$ and $L$-methionine $\left(\mathrm{C}_{5} \mathrm{H}_{11} \mathrm{NO}_{2} \mathrm{~S}\right)$. Research work involving the preparation and characterization of new/modified solid state 
materials in order to explore potential applications is of paramount importance both academically and industrially. Research work involving the preparation and characterization of new/modified solid state materials in order to explore potential applications is of paramount importance both academically and industrially. So, in this context it is worth investigating the influence of large molecular amino acids like aspartic acid $\left(\mathrm{C}_{4} \mathrm{H}_{7} \mathrm{NO}_{4}\right)$ and $L$-citrulline $\left(\mathrm{C}_{6} \mathrm{H}_{13} \mathrm{~N}_{3} \mathrm{O}_{3}\right)$ as additives on the physical properties of KAP.

In the present work, we have grown pure and large molecular amino acid (aspartic acid/L-citrulline) added KAP single crystals by the slow evaporation method and characterized structurally, thermally and mechanically by x-ray diffraction (XRD), thermogravimetric (TG/DTG) and microhardness measurements. The results obtained are reported herein and discussed.

\section{Experimental}

Commercially available analytical reagent (AR) grade chemicals were used for the experimental work. Millipore water with the resistivity of $18.2 \mathrm{M} \Omega \mathrm{cm}$ at $25{ }^{\circ} \mathrm{C}$ was used as the solvent. Pure and amino acid (aspartic acid/ $L$-citrulline) added KAP single crystals were grown at room temperature $\left(32{ }^{\circ} \mathrm{C}\right.$, controlled to an accuracy of $\pm 0.01{ }^{\circ} \mathrm{C}$ ) by the slow evaporation method. Saturated aqueous solutions were prepared in beakers by adding the amino acid in KAP solution as required and stirred well using a magnetic stirrer. Thus prepared solutions were filtered using a micro filter paper and kept in a constant temperature bath. The beakers were covered with perforated sheets and the solutions were allowed to equilibrate. Three different amino acid concentrations viz. $0.01,0.05$ and $0.1 \mathrm{M}$ was considered in each case. So a total of seven crystals were grown. Single crystals with good transparency were harvested within a span of 25 days. Photographs of the sample crystals grown are shown in Figure 1. Hereafter, the grown crystals can be represented as: KAP (pure KAP), LA (0.01 M aspartic acid added KAP), MA (0.05 M aspartic acid added KAP), HA (0.1 M aspartic acid added KAP), LC (0.01 M L-citrulline added KAP), MC (0.05 M Lcitrulline added KAP), HC (0.1 M $L$-citrulline added KAP).
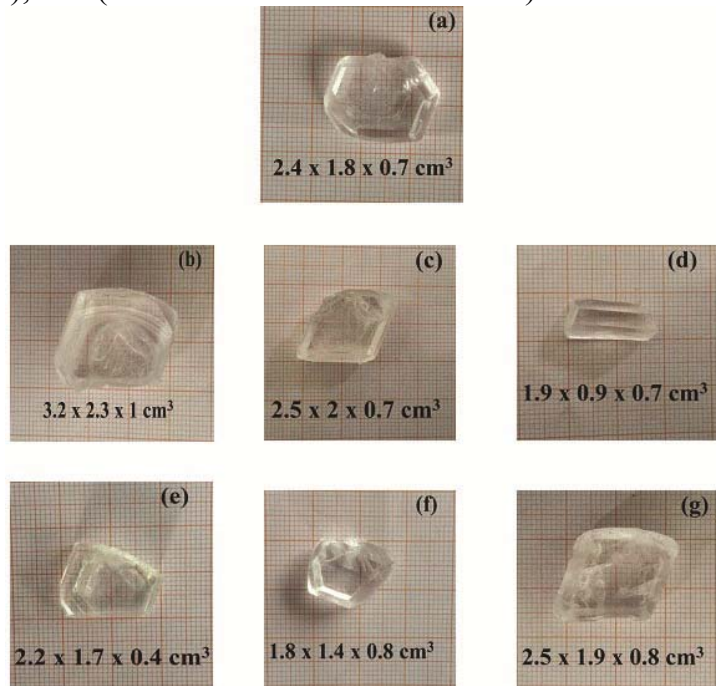

Figure 1. Photographs of the grown crystals: (a) KAP, (b) LA, (c) MA, (d) HA, (e) LC, (f) $\mathrm{MC}$ and (g) $\mathrm{HC}$ 


\section{Results and Discussion}

XRD measurements were carried out on powdered samples of all the seven grown crystals using a Bruker AXS D8 Advance diffractometer equipped with a $2 \theta$ compensating slit with monochromatized $\mathrm{CuK}_{\alpha}$ radiation of wavelength $1.54 \AA$. The data were collected in a continuous scan mode with a step size of $0.02^{\circ}$ and step time of $1 \mathrm{sec}$ over a of $2 \theta$ range of 10 to $50^{\circ}$. The XRD patterns observed in the present study are shown in Figure 2. The sharp peaks observed confirm the crystalline nature of the grown crystals. The patterns observed are in good agreement with that reported in the literature for the pure KAP crystal ${ }^{9}$. This indicates that the material of the grown crystals is basically KAP. The small changes in $2 \theta$ values due to doping indicate that the dopant molecules have entered into the KAP crystal matrix. The reflection peaks were indexed and the lattice parameters were determined using the standard procedures. The obtained lattice parameters are provided in Table 1. The nonobservance of significant changes in the lattice parameters due to doping implies that the crystal structure is not distorted significantly.

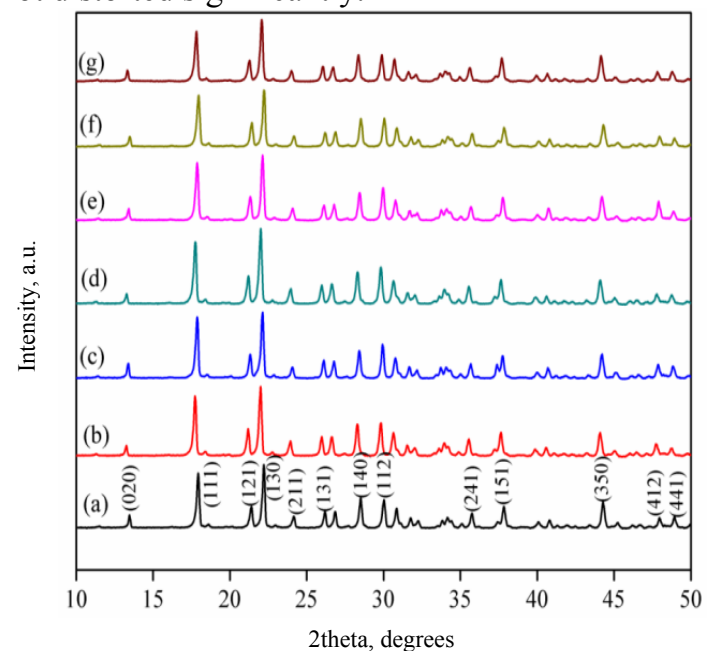

Figure 2. XRD patterns for the grown crystals: (a) KAP, (b) LA, (c) MA, (d) HA, (e) LC, (f) $\mathrm{MC}$ and (g) HC.

Table 1. Lattice parameters for the grown KAP crystals

\begin{tabular}{ccccc}
\hline Crystal & $\mathrm{a}(\AA)$ & $\mathrm{b}(\AA)$ & $\mathrm{c}(\AA)$ & $\mathrm{V}\left(\AA^{3}\right)$ \\
\hline KAP & 9.592 & 13.248 & 6.442 & 818.7 \\
LA & 9.631 & 13.338 & 6.492 & 834.0 \\
MA & 9.603 & 13.280 & 6.481 & 826.6 \\
HA & 9.628 & 13.342 & 6.485 & 833.1 \\
LC & 9.603 & 13.284 & 6.455 & 823.6 \\
MC & 9.614 & 13.314 & 6.477 & 829.2 \\
HC & 9.619 & 13.310 & 6.475 & 829.1 \\
\hline
\end{tabular}

Thermogravimetric analysis (TG/DTG) was carried out for all the seven crystals grown using a TGA Q500 V6.7 Build 203 instrument with pin-holed platinum crucibles heated at $10{ }^{\circ} \mathrm{C} / \mathrm{min}$ under nitrogen atmosphere. The thermal stability of the grown crystals was determined by carrying out thermogravimetric (TG/DTG) measurements. The thermograms obtained in the present study are shown in Figure 3. The TG curve obtained for the pure KAP 
is in good agreement with that reported in the literature ${ }^{10,11}$. The weight loss data are provided in Table 2. Results indicate that LA exhibits maximum thermal stability (up to $217^{\circ} \mathrm{C}$ ) and LC exhibits minimum thermal stability (up to $197^{\circ} \mathrm{C}$ ). Further, non-observance of weight loss within $100{ }^{\circ} \mathrm{C}$ indicates the absence of adsorbed water molecules in the crystal during crystallization. All the crystals except HA exhibit two sharp weight losses. HA exhibits three weight losses; the first two are sharp and the third one is diffuse. This indicates some small distortion created in the crystal due to higher concentrated aspartic acid at higher temperature, after the first decomposition (formation of dipotassium phthalate).
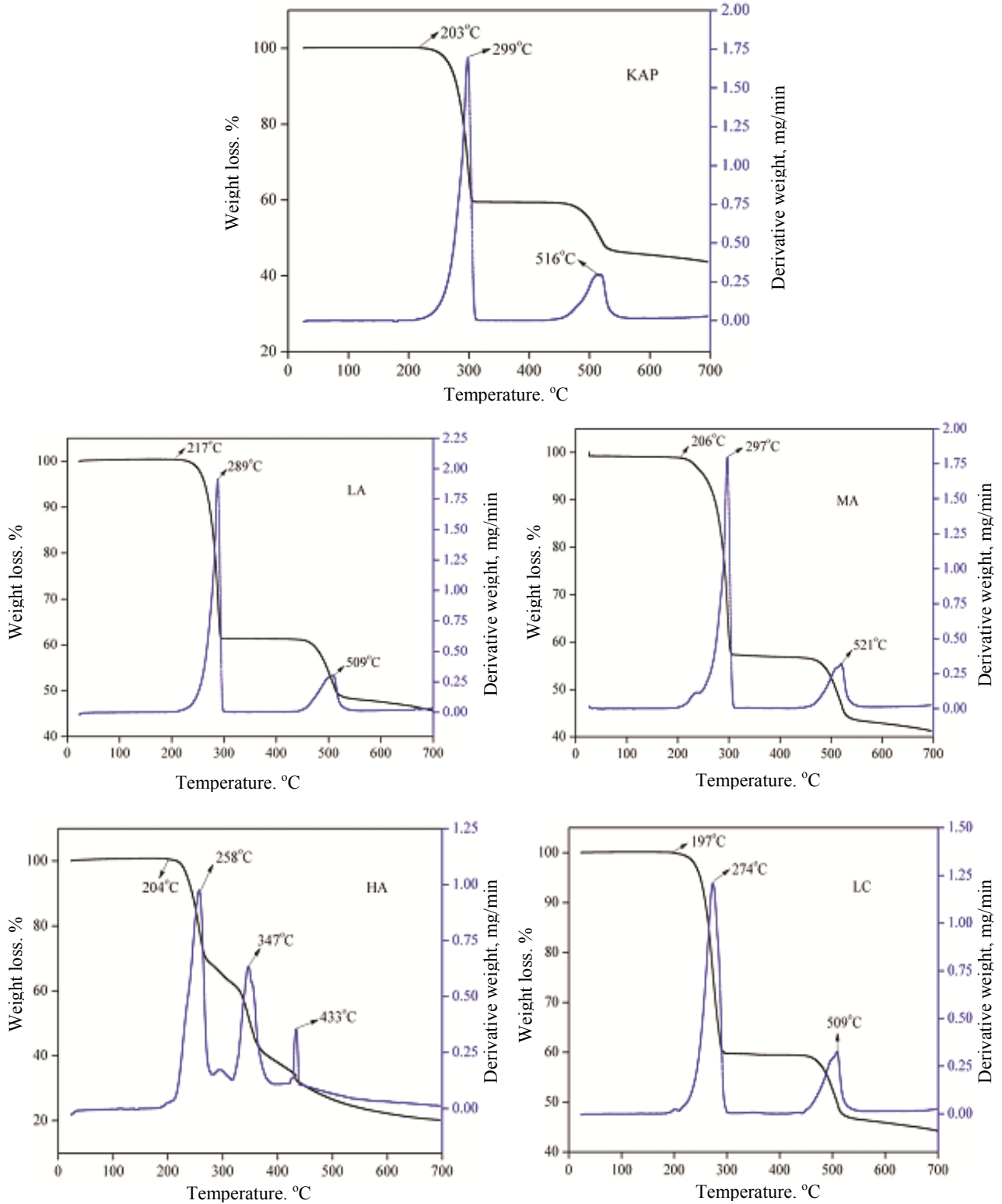

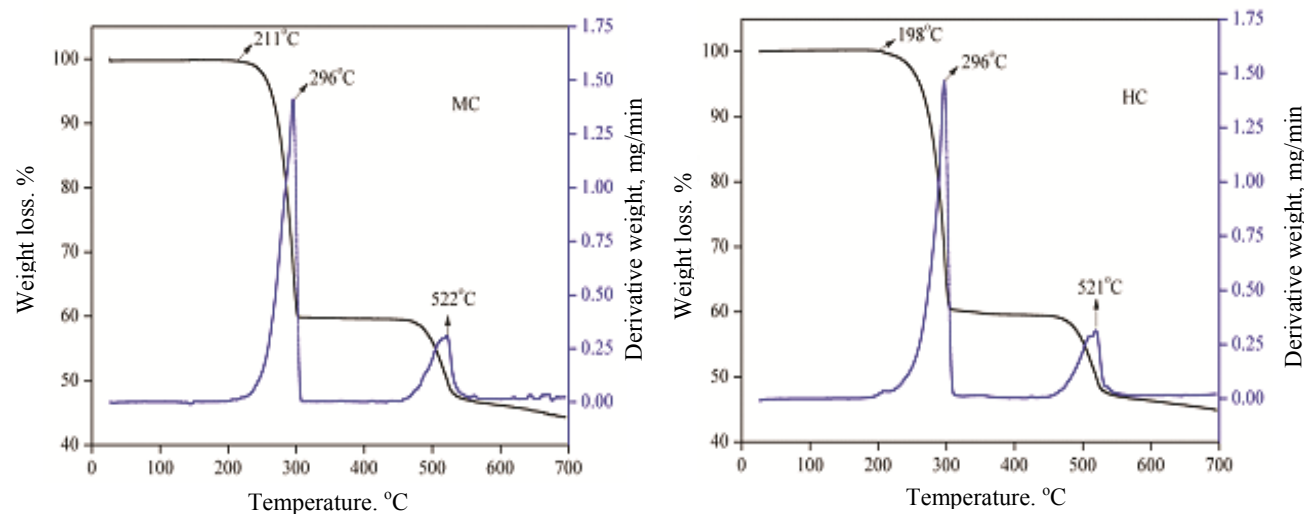

Figure 3. TG/DTG patterns observed for the grown crystals.

Table 2. Decomposition temperatures and percentage weight losses for the grown crystals.

\begin{tabular}{ccccccc}
\hline Crystal & $\begin{array}{c}\text { First } \\
\text { decomposition } \\
\text { temperature, }{ }^{\circ} \mathrm{C}\end{array}$ & $\begin{array}{c}\text { Weight } \\
\text { loss, } \%\end{array}$ & $\begin{array}{c}\text { Rate of } \\
\text { weight loss } \\
\mathrm{mg} / \mathrm{min} \\
\mathrm{At},{ }^{\circ} \mathrm{C}\end{array}$ & $\begin{array}{c}\text { Second } \\
\text { decomposition } \\
\text { temperature, }{ }^{\circ} \mathrm{C}\end{array}$ & $\begin{array}{c}\text { Weight } \\
\text { loss, } \%\end{array}$ & $\begin{array}{c}\text { Rate of } \\
\text { weight loss, } \\
\mathrm{mg} / \mathrm{min} \\
\text { at, }{ }^{\circ} \mathrm{C}\end{array}$ \\
\hline KAP & $203-303$ & 41 & 1.69 at 299 & $458-537$ & 12 & 0.30 at 516 \\
LA & $217-293$ & 39 & 0.59 at 289 & $454-528$ & 13 & 0.29 at 509 \\
MA & $206-306$ & 43 & 1.80 at 297 & $459-550$ & 13 & 0.32 at 521 \\
HA & $204-268$ & 31 & 0.97 at 258 & $228-366$ & 28 & 0.63 at 347 \\
LC & $197-292$ & 41 & 1.21 at 274 & $448-532$ & 11 & 0.32 at 509 \\
MC & $211-305$ & 41 & 1.41 at 296 & $464-538$ & 12 & 0.30 at 522 \\
HC & $198-305$ & 40 & 1.46 at 296 & $461-543$ & 13 & 0.31 at 521 \\
\hline
\end{tabular}

Within the temperature range considered in the present study $\left(30-700{ }^{\circ} \mathrm{C}\right)$, the thermal decomposition of KAP takes place in two stages. In the first stage, dipotassium phthalate is formed with the removal of phthalic anhydride and water from two molecules of KAP. In the second stage, potassium carbonate contaminated with elementary carbon is formed with the evolution of acetaldehyde. The reaction in the two stages can be represented as

$$
2 \mathrm{KC}_{8} \mathrm{H}_{5} \mathrm{O}_{4} \frac{-\left(\mathrm{C}_{8} \mathrm{H}_{4} \mathrm{O}_{3}+\mathrm{H}_{2} \mathrm{O}\right)}{\text { Stage I }} \longrightarrow \mathrm{K}_{2} \mathrm{C}_{8} \mathrm{H}_{4} \mathrm{O}_{4} \frac{-\left(\mathrm{C}_{2} \mathrm{H}_{4} \mathrm{O}\right)}{\text { Stage II }}>\mathrm{K}_{2} \mathrm{CO}_{3}+\text { Carbon }
$$

Microhardness measurements were carried out on $\{010\}$ face of the crystal using a Vickers microhardness tester (Shimadzu HMV-2T) fitted with diamond indenter for three different loads, viz. 25, 50 and $100 \mathrm{~g}$. It is a fact that any material useful for optical devices must satisfy at least a minimum requirement of atmospheric, thermal and mechanical stabilities. In order to understand the mechanical stability of the grown crystals, microhardness measurements have been carried out by using the Vickers indentation method with a constant indentation time of 5 seconds for all loads considered. The Vickers microhardness number was calculated using the relation

$$
\mathrm{H}_{\mathrm{v}}=1.8544 \mathrm{P} / \mathrm{d}^{2}\left(\mathrm{~kg} / \mathrm{mm}^{2}\right)
$$

Where, $\mathrm{P}$ is the applied load and $\mathrm{d}$ is the diagonal length of the impression. Load versus $\mathrm{H}_{\mathrm{v}}$ plots obtained are shown in Figure 4. Results indicate that the hardness value increases with the increase in load for all the seven crystals grown in the present study. Also, the lower 
concentrated doping increases while the middle and higher concentrated doping decreases the hardness value. The changes in the hardness value due the addition of amino acid may be due to the interaction between O-H group of KAP with $\mathrm{COO}$ group of amino acid. Higher the hardness values greater is the stress required to form dislocation, thus confirming greater crystalline perfection especially for the lower concentrated aspartic acid/ $L$-citrulline doped crystals $^{12}$. The well known Meyers relation is stated as

$$
\mathrm{P}=\mathrm{K}_{1} \mathrm{~d}^{\mathrm{n}}
$$

Where, $\mathrm{K}_{1}$ is the standard hardness value (material constant) and $\mathrm{n}$ is the work hardening coefficient (Meyers index number). The $\mathrm{n}$ value can be determined by fitting the hardness data into Meyers relation. Plots between $\log \mathrm{P}$ and $\log \mathrm{d}$ (shown in Figure 5) are found to be nearly linear and the $\mathrm{n}$ value has been determined from the slope of the best fitted straight lines. According to Onitsch, the value of $\mathrm{n}$ should lie between 1 to 1.6 for hard materials and greater than 1.6 for soft materials. In the present study, all the seven grown belongs to the soft material.

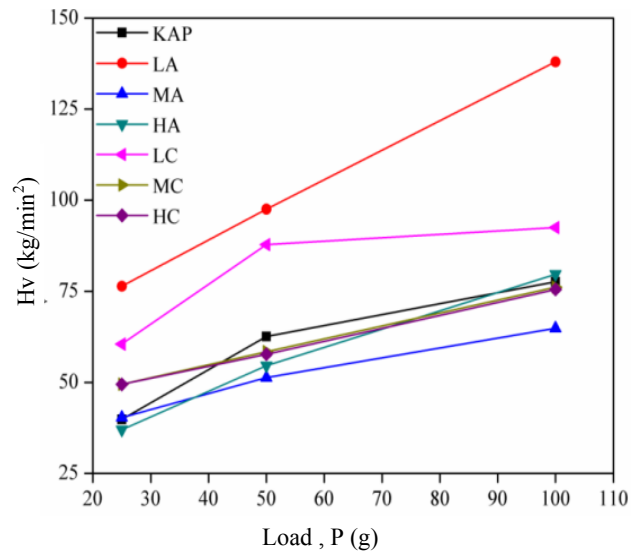

Figure 4. Vickers hardness plots for amino acid added KAP crystals

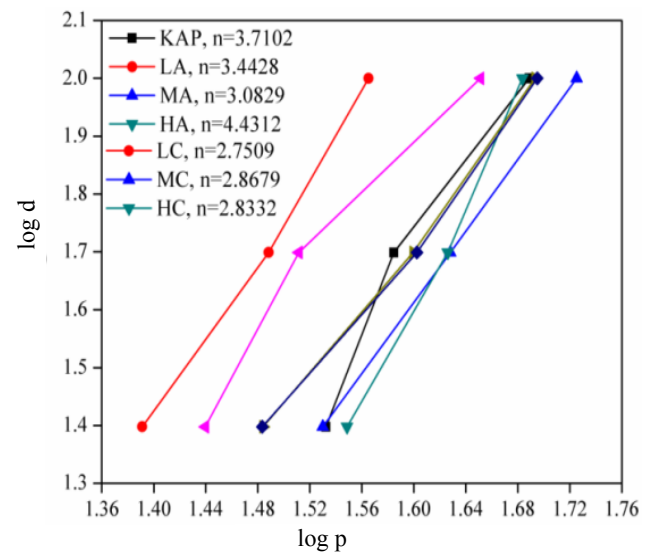

Figure 5. Plots between $\log \mathrm{P}$ and $\log \mathrm{d}$ for amino acid added KAP crystals

\section{Conclusion}

Good quality, atmospherically stable, colourless and transparent single crystals with reasonably good size of pure and aspartic acid/L-citrulline added KAP have been successfully grown by the slow evaporation method at $32{ }^{\circ} \mathrm{C}$. The XRD analysis confirms the basic material of all the seven crystals grown as KAP and also the incorporation of amino acid molecules into the KAP crystal matrix in the case of doped crystals. All the grown crystals are found to be thermally and mechanically stable so that they can very well be utilized in possible devices.

\section{Acknowledgement}

The authors (C Amuthambigai) acknowledge PSN management for providing the research stipend to carry out the work in a great manner. The authors are happy to thank Dr. S. Natarajan, Framework Solids Laboratory, IISc, Bangalore, for providing powder XRD facilities and Dr. U.P. Senthil Kumar, Vice President, Orchid Pharma, Chennai for providing TGA facilities. 


\section{References}

1. Mavrin B N, Koldaeva M V, Zakalyukin R M and Turskaya T N, Optics Spectroscopy, 2006, 100(6), 862-868; DOI:10.1134/S0030400X06060099

2. Andrzej Miniewicz and Stanislaw Bartkiewicz, Adv Mat Optics Electronics, 1993, 2(4), 157-163.

3. Baraniraj T and Philominathan P, J Min Mat Character Engg., 2011, 10, 805-815; DOI:10.4236/jmmce.2011.109062

4. Sivakumar N, Mohankumar R and Anbalagan G, Adv Mat Res., 2012, 584, 116-120.

5. Ferdousi Akhtar and Jiban Podder, J Appl Sci., 2011, 11, 2974-2983.

6. Uthayarani K, Sankar R and Shashidharan Nair C K, Cryst Res Technol., 2008, 43(7), 733-739; DOI:10.1002/crat.200711091

7. Elakkina Kumaran A, Kanchana P and Sekar C, Spectrochim Acta Part A: Mole Biomole Spectr., 2012, 91, 370-374; DOI:10.1016/j.saa.2012.01.067

8. Thilagavathy S R, Rajesh P, Ramasamy P and Ambujam K, Spectrochim Acta Part A: Mole Biomole Spectr., 2014, 127, 248-255; DOI:10.1016/j.saa.2014.01.137

9. Okaya Y, Acta Crystallographica, 1965, 19(6), 879-882;

DOI:10.1107/S0365110X65004590

10. Newkirk A E and Renette Laware, Talanta, 1962, 9(2), 169-173; DOI:10.1016/00399140(62)80039-3

11. Belcher R, Erdey L, Paulik F and Liptay G, Talanta, 1960, 5(1), 53-57.

12. Ruby Nirmala L and Thomas Joseph Prakash J, Spectrochim Acta Part A: Mole Biomole Spectr., 2013, 110, 425-429; DOI:10.1016/j.saa.2013.03.070 